\title{
Apelin: new treatment for postoperative cognitives dysfunction?
}

\author{
Delort F. ${ }^{*}$, Labaste F. ${ }^{23}$, Vinel $C_{.}^{2}$, Frances B. $^{3}$, Dray $C_{.}{ }^{2}$, Minville V. ${ }^{2}$
}

'Toulouse University Hospitals, Dept of Anaesthesiology \& Intensive Care, Toulouse, France, ${ }^{2}$ INSERM I2MC équipe3, Research and Development Dept, Toulouse, France, ${ }^{3}$ CRCA, équipe MPV, CNRS, Toulouse, France

Introduction : Postoperative cognitive dysfunction (POCD) is a common complication after surgery, especially amongst elderly patients. They are associated with increased dependence, postoperative morbidity and mortality. To date, there is no preventive treatement.

The main physiopathological hypothesis is based on the occurrence of postoperative neuroinflammation.

Because apelin is an adipokin with anti-inflammatory and neuroprotective proprieties, we want to investigated the effect of postoperative apelin treatment to prevent POCD.

\section{POCD model : Fear Conditionning}

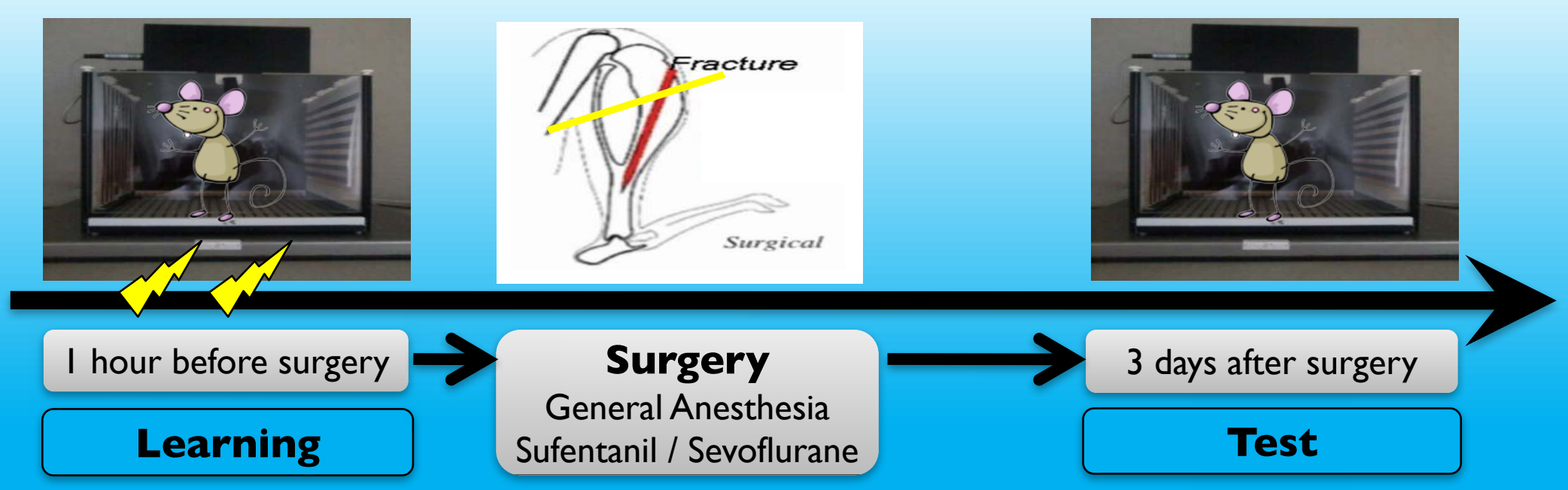

Test : During 4 minutes, mice was observed. We were hoping for fearful behavior : freezing During test period, if mice didn't have mémory problems, freezing was observed

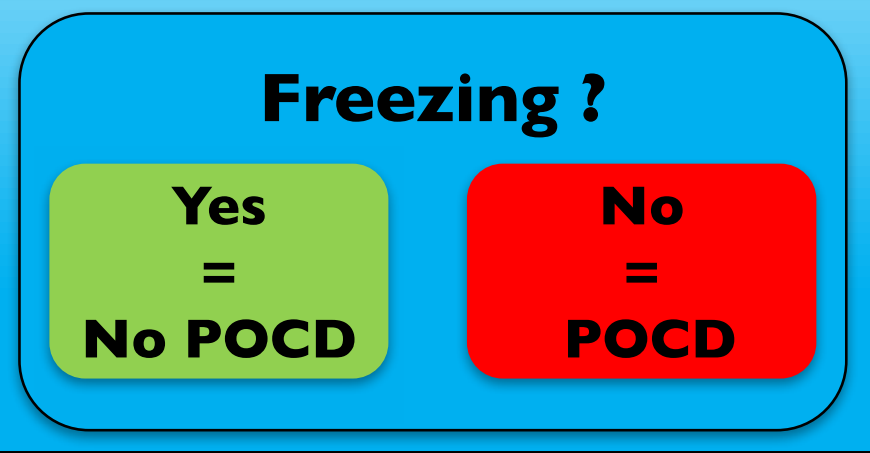

Surgery induce POCD on mice

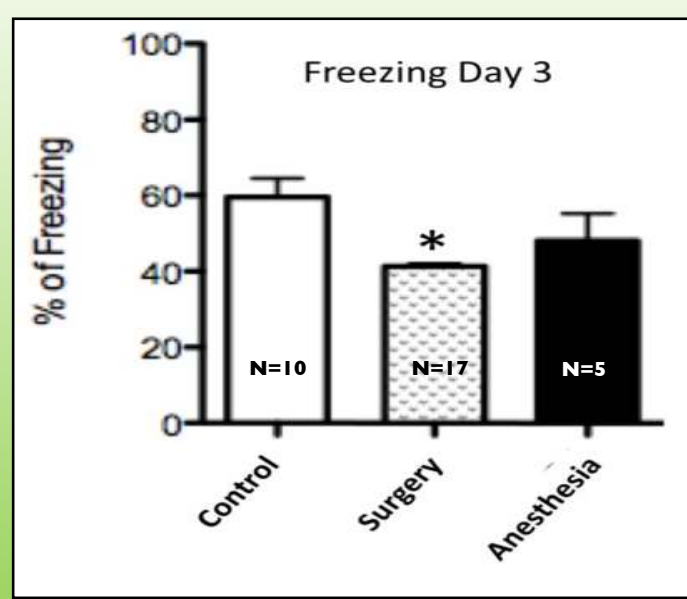

Result : After surgery, mice had a significantly reduced freezing rate compared to control mice ( $35 \%$ vs $57 \%, \mathrm{p}<0.05$ ). After anesthesia alone, mice had the same freezing rate compared to contol mice.

\section{Apelin prevent POCD on mice}

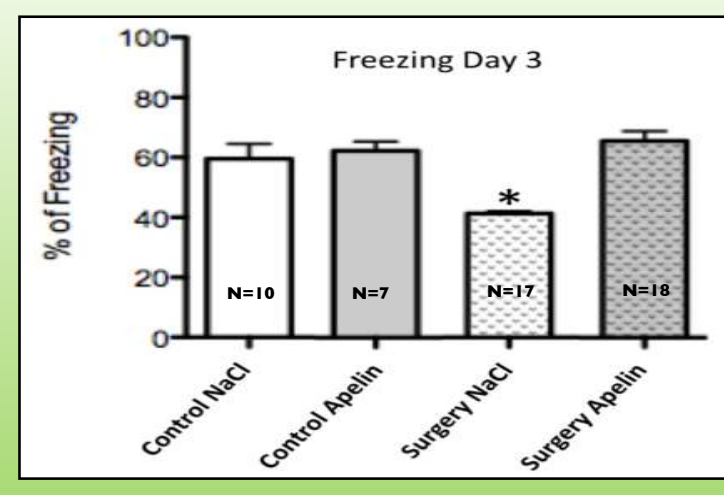

\section{Apelin treatment $0,5 \mu \mathrm{mol} / \mathrm{kg} / \mathrm{day}$ \\ First injection : I hour before surgery}

Result : Apelin warned POCD, level of freezing was similar after surgery in mouse with apelin treatment. Freezing rate was similar on control mice and surgery apelin mice ( $57 \%$ vs $65 \%$, NS). Apelin did not improved memory capacities, freezing was similar in control mice without or with apelin treatment ( $57 \%$ vs $62 \%$, NS).

\section{Apelin prevent postoperative inflammation}
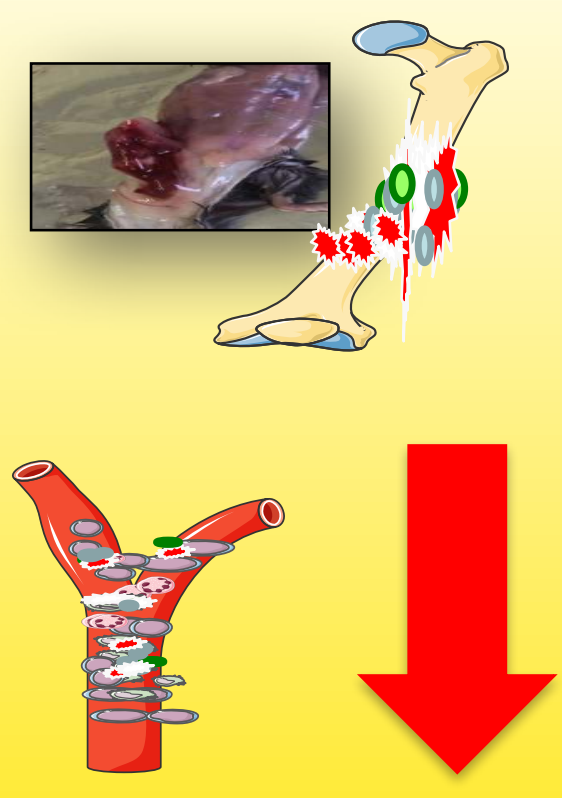

Blood - Apelin reduce plasma level of inflammatory cytokine : IL6

ematoma - Apelin reduce expression of inflammatory cytokine : IL6 and TNF $\alpha$
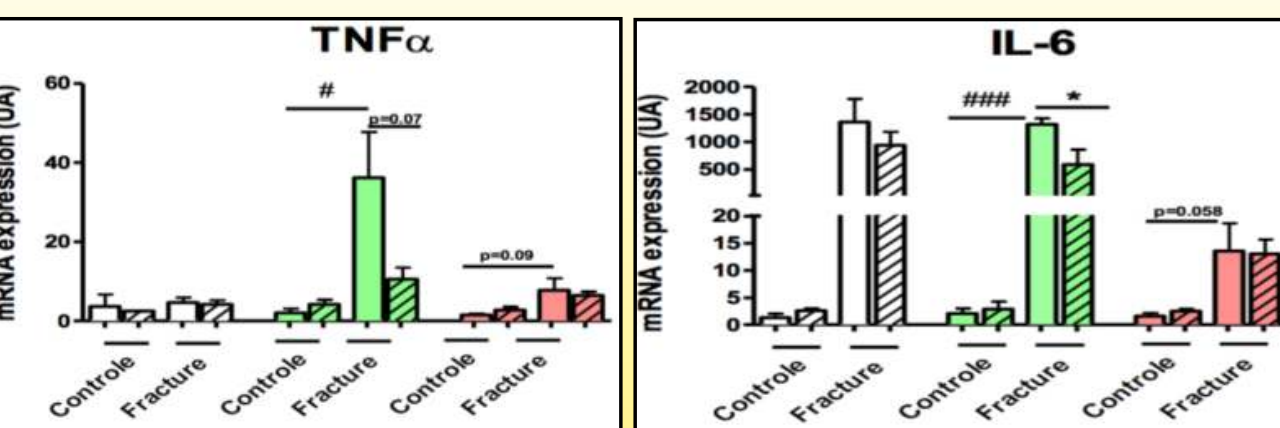

$\square$ 3hPBS $\square$ 6hPBS $\square$ 24hPBS

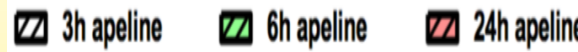

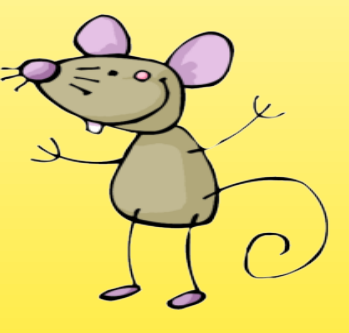
Brain - Apelin reduce expression TNF $\alpha$

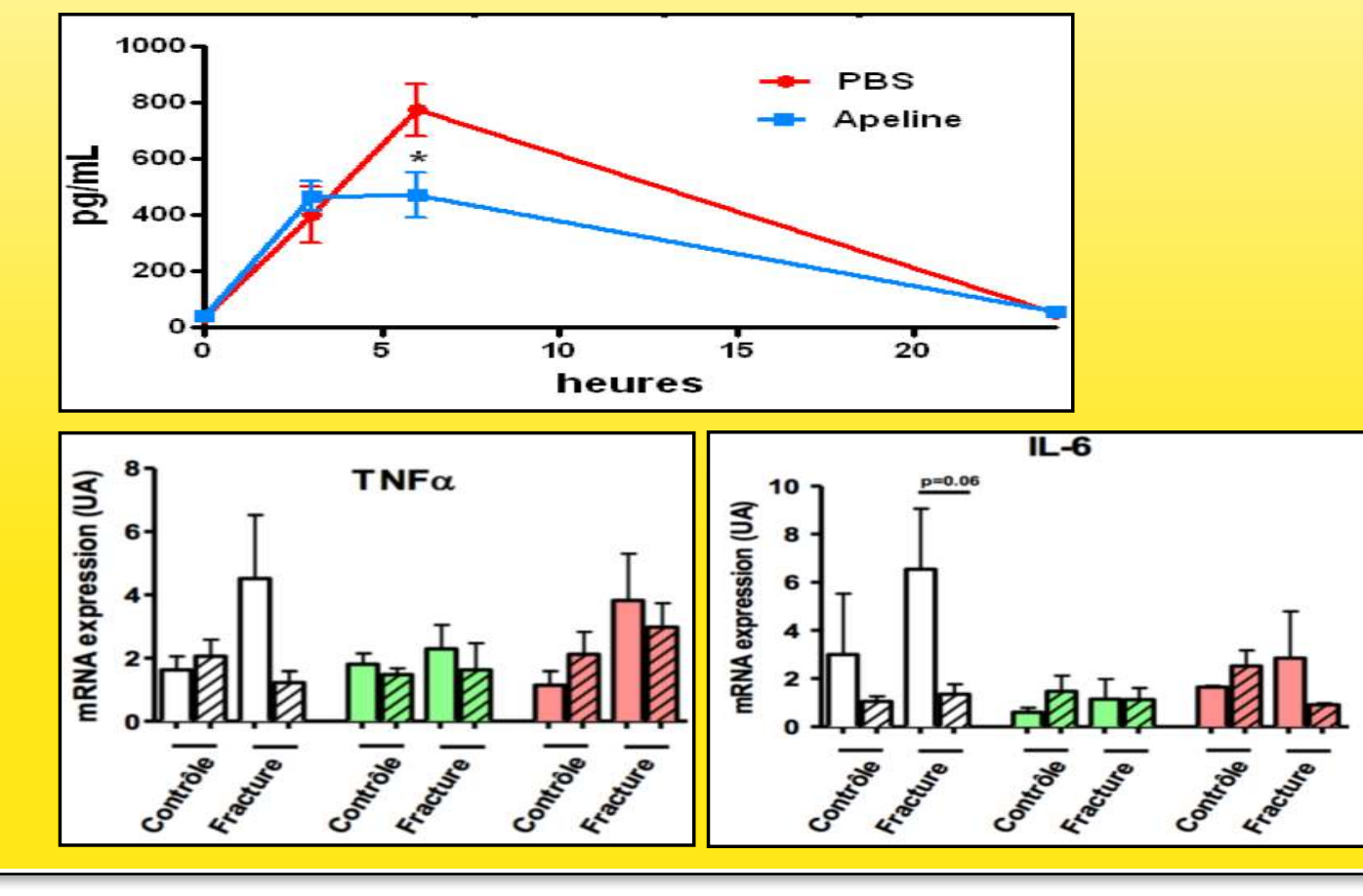

$\square$ 3hPBS $\square$ 6hPBS $\square$ 24hPBS $\square$ Sh apeline $\square$ 6h apoline $\square$ 2hapaline

\section{Conclusions - Perspectives}

- In mice, perioperative treatment with apeline reduced postoperative cerebral inflammation and prevent the POCD development. Apeline appears to be a promising treatment of POCD.

- In future, we need to understand the actions pathways of apelin, and identify targets cells population.

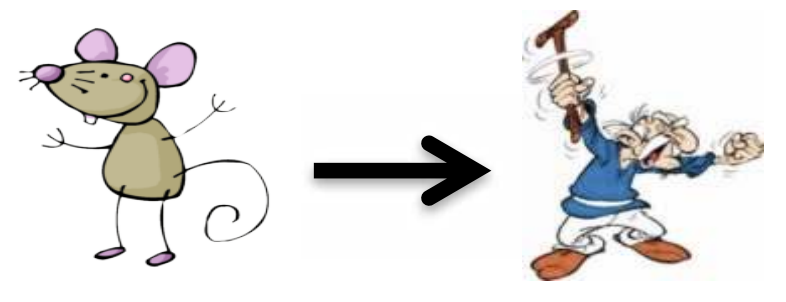

